\title{
Optimization of Carboxymethyl-Xyloglucan-Based Tramadol Matrix Tablets Using Simplex Centroid Mixture Design
}

\author{
Ashwini R. Madgulkar, Mangesh R. Bhalekar, Rahul R. Padalkar, and Mohseen Y. Shaikh \\ Department of Pharmaceutics, AISSMS College of Pharmacy, Kennedy Road, Pune 411001, Maharashtra, India \\ Correspondence should be addressed to Ashwini R. Madgulkar, ashwini.madgulkar@indiatimes.com
}

Received 12 July 2012; Accepted 26 September 2012

Academic Editor: Nayanabhirama Udupa

Copyright (C) 2013 Ashwini R. Madgulkar et al. This is an open access article distributed under the Creative Commons Attribution License, which permits unrestricted use, distribution, and reproduction in any medium, provided the original work is properly cited.

\begin{abstract}
The aim was to determine the release-modifying effect of carboxymethyl xyloglucan for oral drug delivery. Sustained release matrix tablets of tramadol $\mathrm{HCl}$ were prepared by wet granulation method using carboxymethyl xyloglucan as matrix forming polymer. HPMC K100M was used in a small amount to control the burst effect which is most commonly seen with natural hydrophilic polymers. A simplex centroid design with three independent variables and two dependent variables was employed to systematically optimize drug release profile. Carboxymethyl xyloglucan $\left(X_{1}\right)$, HPMC K100M $\left(X_{2}\right)$, and dicalcium phosphate $\left(X_{3}\right)$ were taken as independent variables. The dependent variables selected were percent of drug release at 2nd hour $\left(Y_{1}\right)$ and at 8 th hour $\left(Y_{2}\right)$. Response surface plots were developed, and optimum formulations were selected on the basis of desirability. The formulated tablets showed anomalous release mechanism and followed matrix drug release kinetics, resulting in regulated and complete release from the tablets within 8 to 10 hours. The polymer carboxymethyl xyloglucan and HPMC K100M had significant effect on drug release from the tablet $(P>0.05)$. Polynomial mathematical models, generated for various response variables using multiple regression analysis, were found to be statistically significant $(P>0.05)$. The statistical models developed for optimization were found to be valid.
\end{abstract}

\section{Introduction}

Hydrophilic matrices are an interesting option while developing an oral sustained-release formulation. They can be used for controlled release of both water-soluble and waterinsoluble drugs. The release behaviour of drugs varies with the nature of the matrix and it is the complex interaction of swelling, diffusion, and erosion processes [1]. Polysaccharides are the choice of material which has been evaluated as hydrophilic matrix for drug delivery system due to their nontoxicity and acceptance by regulating authorities.

Xyloglucan is a natural polysaccharide isolated from seed kernel of Tamarindus indica. It is used as ingredient in food and pharmaceutical industry. It has been significantly evaluated for use in hydrophilic drug delivery system. It possesses high viscosity, broad $\mathrm{pH}$ tolerance, and swelling and binding properties [2]. This led to its application as release retardant polymer and binder in pharmaceutical industry. In addition to these, other important properties of xyloglucan have been identified recently, which include noncarcinogenicity [3], mucoadhesivity, biocompatibility [4], high drug holding capacity [5], and high thermal stability [6]. This led to its application as excipient in hydrophilic drug delivery system [3-6].

Carboxymethyl xyloglucan is a derivative of xyloglucan and the microbial resistance of CM-xyloglucan is much better than that of plain powder. The viscosity of CM-xyloglucan in solutions is higher compared to native gum. Derivatization of xyloglucan, that is, CM-xyloglucan, disrupts the organization and exposes the polysaccharide network for hydration which results in higher viscosity and due to this its swelling index is also higher as compared to Xyloglucan. The presence of carboxymethyl groups makes the molecule resistant toward enzymatic attack [7]. Since carboxymethyl xyloglucan is having improved properties which are required for the retardation of release, the present study was undertaken to elucidate release kinetics of water-soluble drug from the matrix.

Tramadol, a synthetic opioid of the aminocyclohexanol group, is a centrally acting analgesic with weak opioid agonist properties. The half-life of the drug is about 5.5 hours and the usual oral dosage regimen is 50 to $100 \mathrm{mg}$ every 4 to 6 
hours with a maximum dosage of $400 \mathrm{mg} /$ day [8]. To reduce the frequency of administration and to improve patient compliance, a sustained-release formulation of tramadol is desirable. The drug is freely soluble in water and hence judicious selection of release retarding excipients is necessary to achieve a constant in vivo input rate of the drug. The most commonly used method of modulating the drug release is to include it in a matrix system [9]. The major objective of the present investigation was to develop a sustained-release drug delivery system using simplex centroid design as an optimization technique.

\section{Material and Methods}

Carboxymethyl xyloglucan (CM-xyloglucan) was procured from Encore Natural Polymer Private Limited, Ahmedabad. HPMC (K100 M), dicalcium phosphate were purchased from SD Fine Chemicals Ltd (Mumbai, India). PVP K-30 was procured from Loba Chemicals (Mumbai, India). Tramadol $\mathrm{HCl}$ was a gift sample from Rantus Pharma Ltd (Hyderabad). All the other chemicals used were of high analytical grade.

\subsection{Methods}

2.1.1. Preparation of Matrix Tablets. Matrix tablets, each containing $100 \mathrm{mg}$ of Tramadol $\mathrm{HCl}$, were prepared. For determining levels of carboxymethyl xyloglucan, initial trial batches with different concentrations of carboxymethyl xyloglucan were prepared and evaluated for physicochemical properties of formulation and dissolution studies. In the trial runs, carboxymethyl xyloglucan concentration was varied from 50 to $250 \mathrm{mg}$. It was observed that as the concentration of carboxymethyl xyloglucan increased, the retarding effect of the formulation also increased, but a phenomenon of burst effect was prominently seen in all the formulations (Figure 1). Hence, to prevent the burst effect HPMC K100M was used. The quantities of other ingredients were kept constant, that is, DCP at $20 \mathrm{mg}$. Magnesium stearate and talc at $5 \mathrm{mg}$ were used as a lubricant and a glidant, respectively.

Different tablet formulations were prepared by wet granulation technique. All the powders were passed through a sieve of 80 mesh size. Required quantities of drug, polymer, and dicalcium phosphate were mixed thoroughly and a sufficient volume of granulating agent (isopropyl alcohol solution of PVP K-30) was added slowly. After enough cohesiveness was obtained, the mass was sieved through $22 / 44$ mesh. The granules were dried at room temperature. Once dry, the granules retained on 44 mesh were mixed with $15 \%$ of fines (granules that passed through 44 mesh). Talc and magnesium stearate were finally added as glidant and lubricant, respectively. The tablets were compressed $(10 \mathrm{~mm}$ diameter, flat punches) using a tablet compression machine, Mini Press-II MT, Rimek. Each tablet contained $100 \mathrm{mg}$ of tramadol $\mathrm{HCl}$ and other pharmaceutical ingredients. Prior to the compression, the granules were evaluated for several tests.

2.1.2. Evaluation of Tablets. The tablets were evaluated for different physicochemical parameters such as angle of repose

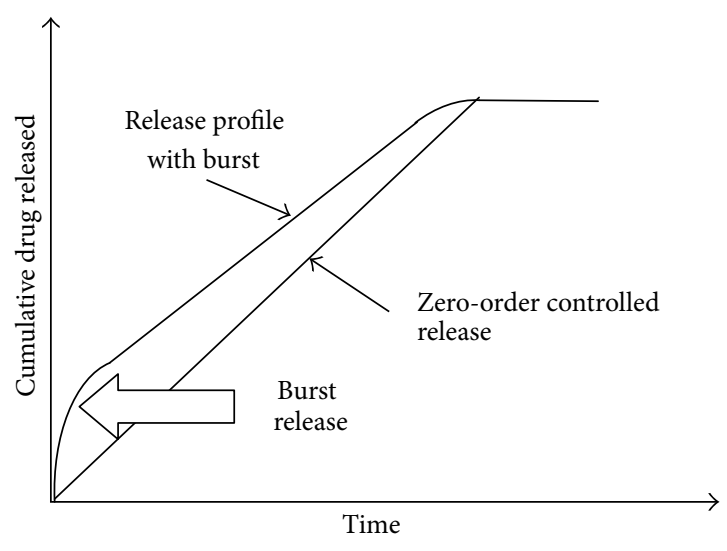

FIGURE 1: Diagram indicating the burst effect phenomenon.

[10], thickness, bulk density, tap density [11], Carr's index [12], weight variation, thickness, hardness, friability, weight variation [13], drug content, and in vitro release. In drug content, 20 tablets of each formulation were weighed and powdered. The quantity of powder equivalent to $100 \mathrm{mg}$ of tramadol $\mathrm{HCl}$ was taken and dissolved in $30 \mathrm{~mL}$ of distilled water; sufficient amount distilled water was added to produce $50 \mathrm{~mL}$ and was filtered. The absorbance was measured spectrophotometrically at $271 \mathrm{~nm}$ after suitable dilution. The in vitro dissolution studies were carried out using USP apparatus type II (DA 6D, Veego) at $100 \mathrm{rpm}$. The dissolution medium consisted of $0.1 \mathrm{~N}$ hydrochloric acid for the first 2 hours and the phosphate buffer $\mathrm{pH} 6.8$ from 3 to 8 hours $(900 \mathrm{~mL})$, maintained at $37^{\circ} \mathrm{C} \pm 0.5^{\circ} \mathrm{C}$. The drug release at different time intervals was measured by UV-visible spectrophotometer (V-530, Jasco) at $271 \mathrm{~nm}$. The release studies were conducted in triplicate (6 tablets in each set) and the mean values were plotted versus time with standard deviation (SD) of less than 3 , indicating the reproducibility of the results.

Kinetic Modeling of Drug Release. The dissolution profile of all the batches was fitted to various models such as zeroorder, first-order [14], MatrixT [15], Hixon-Crowell [16], Korsmeyer et al. and Peppas [17, 18], and Weibull models to ascertain the kinetic modeling of drug release. The method of Bamba et al. [19] was adopted for deciding the most appropriate model.

Swelling Index. The extent of swelling was measured in terms of percent weight gain by the tablet [20]. The swelling behavior of all formulations was studied. One tablet from each formulation was kept in separate Petri dishes containing $0.1 \mathrm{~N} \mathrm{HCl}$ for first 2 hours and then was placed in phosphate buffer $\mathrm{pH} 6.8$ till 8 hours. At the end of every 1 hour interval, the tablet was withdrawn, soaked with tissue paper, and weighed. This process was continued till the end of 8 hours. Percentage weight gain by the tablets was calculated by formula

$$
\mathrm{SI}=\left\{\frac{\left(M_{t}-M_{0}\right)}{M_{0}}\right\} \times 100,
$$


where, SI is the swelling index, $M_{t}$ is the weight of swollen tablets at respective time intervals, and $M_{0}$ is the weight of tablet at time $(t)=0$.

Similarity Factor. The similarity factor $(f)$ is used for release profile comparison between the test formulation and marketed preparation [21]. It is a logarithmic transformation of the sum squared error of differences between the test $T_{j}$ and reference products $R_{j}$ over all time points:

$$
f_{2}=50 \times \log \left\{\left[1+\left(\frac{1}{n}\right) \sum_{j=1}^{n}\left|R_{j}-T_{j}\right|^{2}\right]^{-0.5} \times 100\right\},
$$

where " $n$ " is number of pull points, " $R_{j}$ " is reference profile at time point $t$, and " $T$ " is test profile at same time point $t$. The similarity factor fits the result between 0 and 100 as shown in Table 11. It is 100 when test and reference profile are identical and tends to 0 when dissimilarity increases.

Simplex Centroid Design. A simplex centroid design [22] was adopted to optimize the formulation variables. In this design three factors were evaluated by changing their concentrations simultaneously and keeping their total concentration constant. The simplex centroid design for a 3-component system $(A, B$, and $C)$ is represented by an equilateral triangle in a 2-dimensional space (Figure 2). The amounts of matrixing agent carboxymethyl xyloglucan (carboxymethyl xyloglucan, $X_{1}$ ), gelling agent (HPMC K100M, $X_{2}$ ), and dicalcium phosphate (DCP, $X_{3}$ ) were selected as independent variables as shown in Table 3. Percent release values of drug at 2 nd hour and 8th hour were selected as dependent variables. The levels of the three factors were selected on the basis of the preliminary studies carried out before implementing the experimental design.

2.2. Statistical Analysis. The statistical analysis of the simplex centroid design batches was done using Design-Expert 8.0.5 software. To study the influence of each factor on response and behavior of the system within the designed space, response surface plots were generated.

\section{Result and Discussion}

3.1. Preliminary Trials. In trial batches from $A_{1}$ to $A_{5} \mathrm{CM}$ xyloglucan was used in the range of 50 to $250 \mathrm{mg}$ (Table 1); it displayed a retardation of drug release commensurate to the concentration of polymer.

For the comparison of native xyloglucan and derivative carboxymethyl xyloglucan, trial batches $M_{1}$ and $M_{2}$ each containing $150 \mathrm{mg}$ polymer were prepared (Table 12). Batch $M_{1}$ containing plain xyloglucan sustained-release only for 4 hours while batch $M_{2}$ containing CM-xyloglucan sustainedrelease up to 7 hours (Figure 10).

The percentage drug release at second hour for $A_{1}$ to $A_{5}$ formulations was in the range of $87.90 \%$ to $53.39 \%$, respectively, as shown in Figure 3, while only $A_{3}$ to $A_{5}$ formulations were able to retard drug release up to 7 to 8 hours. It was found from the initial trials that 150 to $250 \mathrm{mg}$ of

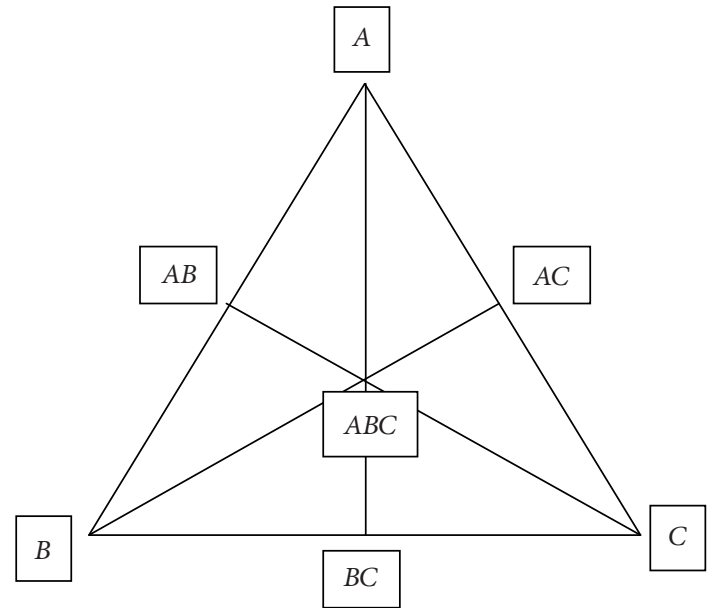

FIGURE 2: Equilateral triangle representing simplex lattice design for 3 components $(A, B$, and $C$ ).

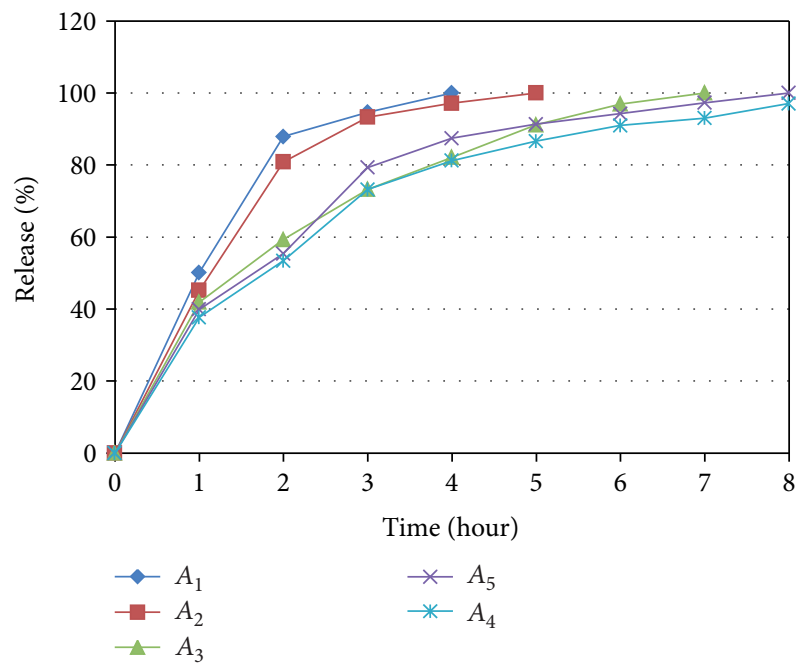

FIGURE 3: Dissolution profile for batches $A_{1}$ to $A_{5}$.

polymer is required for sustaining drug release up to 8 hours, while only $A_{3}$ to $A_{5}$ formulations were able to retard drug release up to 7 to 8 hours. But at $150 \mathrm{mg}$ concentration $\left(A_{3}\right.$ batch) release was sustained up to 7 hours so that minimum level should be slightly more than $150 \mathrm{mg}$, while for 200 and $250 \mathrm{mg}$ concentration release was almost similar, hence, $200 \mathrm{mg}$ was decided as a higher level of the polymer.

The granule characterization of the trial batch formulations $\left(A_{1}\right.$ to $\left.A_{5}\right)$ was performed. The results of this study are depicted in Table 2 which shows excellent flow properties and compressibility.

3.2. Swelling Study. Swelling study results showed slow and gradual increase in swelling index with time and concentration of CM-xyloglucan, as CM-xyloglucan does not swell instantaneously as soon as it comes in contact with water as shown in Figure 4; this results in burst release due to improper swelling. Therefore, to avoid the burst release effect, we have added HPMC K100 in the small quantity. Swelling 
TABLE 1: Trial batch formulations from $A_{1}$ to $A_{5}$.

\begin{tabular}{|c|c|c|c|c|c|}
\hline \multirow{2}{*}{ Ingredients } & \multicolumn{5}{|c|}{ Formulations } \\
\hline & $A_{1}$ & $A_{2}$ & $A_{3}$ & $A_{4}$ & $A_{5}$ \\
\hline Tramadol HCl & 100 & 100 & 100 & 100 & 100 \\
\hline TSP & 50 & 100 & 150 & 200 & 250 \\
\hline HPMC K100M & - & - & - & - & - \\
\hline $\mathrm{DCP}$ & 20 & 20 & 20 & 20 & 20 \\
\hline Talc & 5 & 5 & 5 & 5 & 5 \\
\hline Magnesium Stearate & 5 & 5 & 5 & 5 & 5 \\
\hline PVP K-30 & 30 & 30 & 30 & 30 & 30 \\
\hline Isopropyl alcohol & qs. & qs. & qs. & qs. & qs. \\
\hline Total & 210 & 260 & 310 & 360 & 410 \\
\hline
\end{tabular}

TABLE 2: Dissolution model for formulations from $A_{1}$ to $A_{5}$.

\begin{tabular}{lcccc}
\hline Batch code & Release exponent $(n)$ & Kinetic constant $(K)$ & $R$ & Best fit model \\
\hline$A_{1}$ & 0.6948 & 32.71 & 0.9692 & Matrix \\
$A_{2}$ & 0.7634 & 28.67 & 0.9736 & Matrix \\
$A_{3}$ & 0.7791 & 25.36 & 0.9795 & Matrix \\
$A_{4}$ & 0.8372 & 19.82 & 0.9817 & Matrix \\
$A_{5}$ & 0.6834 & 15.26 & 0.9854 & Matrix \\
\hline
\end{tabular}

Non-Fickian.

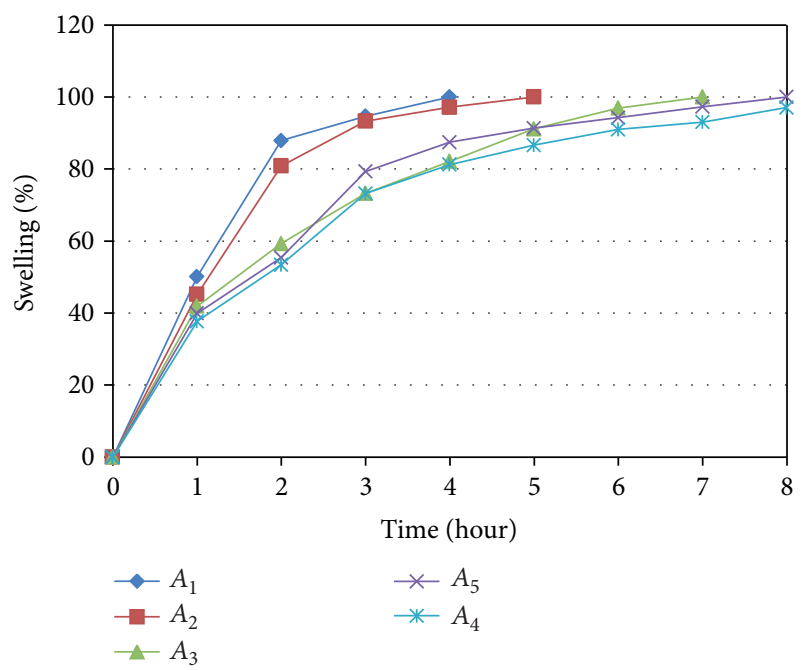

FIgURE 4: Swelling index for $A_{1}$ to $A_{5}$ formulations.

of $A_{5}$ batch is highest because it contains a higher amount of polymer. If swelling is more then it increases the path length required for water to travel inside the core of tablet, which gives more sustained-release.

3.3. Optimization of the Release Rate of Tramadol HCl. The simplex mixture designs are useful when the performance of formulation depends upon relative proportion of ingredients and not on the concentration. The amount of ingredients can be varied keeping the total concentration constant. This design is useful in formulation situations.
TABLE 3: Coded levels and their corresponding actual values of ingredients.

\begin{tabular}{lccc}
\hline Coded & \multicolumn{3}{c}{ Actual values } \\
level & Carboxymethyl xyloglucan & HPMC (K100M) & DCP \\
\hline 0 & 180 & 10 & 30 \\
0.33 & 186.67 & 16.67 & 36.67 \\
0.5 & 190 & 20 & 40 \\
1 & 200 & 30 & 50 \\
\hline All quantities in mg. & &
\end{tabular}

Simplex centroid mixture design is selected for optimization of excipient levels when there are more than two variables. In this design, all the factors are studied in all the possible combinations, as it is considered to be most efficient in estimating the influence of individual variables (main effects) and their interactions, using minimum experimentation. The amounts of matrixing agent $\mathrm{CM}$-xyloglucan $\left(X_{1}\right)$, gelling agent (HPMC K100M, $X_{2}$ ), and dicalcium phosphate (DCP, $X_{3}$ ) were selected as independent variables. Percent release values of drug at second hour and eighth hour were selected as dependent variables. Dissolution profile of USFDA approved tramadol $\mathrm{HCl}$ twice a day. SR tablets gave the following limit for percent drug release $1 \mathrm{hr}(20-50)$, $2 \mathrm{hr}(40-75), 4 \mathrm{hr}(60-95), 8 \mathrm{hr}(80-100)$, and $12 \mathrm{hr}(90-100)$ [23]. To optimize the formulation for acceptance criteria, that is, percent drug release at second hour ( $\mathrm{rel}_{2} \mathrm{Hr}$ ) should be in between 20 to 50 and percent drug release at eighth hour $\left(\mathrm{rel}_{8} \mathrm{Hr}\right.$ ) should be in between 80 to 100 , a simplex centroid design was used. The levels of the three factors were selected on the basis of the preliminary studies carried out 
TABle 4: Composition of $F_{1}$ to $F_{7}$ formulations.

\begin{tabular}{|c|c|c|c|c|c|c|c|}
\hline \multirow{2}{*}{ Ingredients } & \multicolumn{7}{|c|}{ Formulations (mg) } \\
\hline & $F_{1}$ & $F_{2}$ & $F_{3}$ & $F_{4}$ & $F_{5}$ & $F_{6}$ & $F_{7}$ \\
\hline Tramadol $\mathrm{HCl}$ & 100 & 100 & 100 & 100 & 100 & 100 & 100 \\
\hline Carboxymethyl xyloglucan & 200 & 180 & 180 & 190 & 190 & 180 & 186.67 \\
\hline HPMC-k-100M & 10 & 30 & 10 & 20 & 10 & 20 & 16.67 \\
\hline DCP & 30 & 30 & 50 & 30 & 40 & 40 & 36.67 \\
\hline Talc & 5 & 5 & 5 & 5 & 5 & 5 & 5 \\
\hline Magnesium stearate & 5 & 5 & 5 & 5 & 5 & 5 & 5 \\
\hline PVP K-30 & 30 & 30 & 30 & 30 & 30 & 30 & 30 \\
\hline Isopropyl alcohol & qs. & qs. & qs. & qs. & qs. & qs. & qs. \\
\hline Total & 380 & 380 & 380 & 380 & 380 & 380 & 380 \\
\hline
\end{tabular}

All quantities in $\mathrm{mg}$.

before implementing the experimental design. 7 formulations $\left(F_{1}-F_{7}\right)$ were prepared as per the experimental design and evaluated for chosen response variables (Tables 4 and 6).

Hence, it was decided to optimize the amount of CMxyloglucan between 180 to $200 \mathrm{mg}$ per tablet in order to have a sustained and complete release of drug at the end of eight to twelve hours. The amounts of matrixing agent carboxymethyl xyloglucan (CM-xyloglucan, $X_{1}$ ), gelling agent (HPMC K100M, $X_{2}$ ), and dicalcium phosphate (DCP, $X_{3}$ ) were selected as independent variables. A statistical model incorporating 7 interactive terms was used to evaluate the responses:

$$
\begin{aligned}
Y= & b_{0}+b_{1} X_{1}+b_{2} X_{2}+b_{3} X_{3}+b_{8} X_{1} X_{2}+b_{23} X_{2} X_{3} \\
& +b_{13} X_{1} X_{3}+b_{83} X_{1} X_{2} X_{3},
\end{aligned}
$$

where $Y$ is the dependent variable, $b_{0}$ is the arithmetic mean response of the 7 runs, and $b_{i}$ is the estimated coefficient for the factor $X_{i}$. The main effects $\left(X_{1}, X_{2}\right.$, and $\left.X_{3}\right)$ represent the average result of changing one factor at a time from its low to high value. The interaction terms $\left(X_{1} X_{2}, X_{2} X_{3}, X_{1} X_{3}\right.$, and $X_{1} X_{2} X_{3}$ ) show how the response changes when two or more factors are simultaneously changed. The $\mathrm{rel}_{2} \mathrm{Hr}$ and $\mathrm{rel}_{8} \mathrm{Hr}$, respectively, for all 7 batches $\left(F_{1}-F_{7}\right)$ showed a wide variation (Figure 5). The data clearly indicate that the values of drug release are strongly dependent on the selected independent variables.

To demonstrate graphically the effect of release modifying polymers on the dissolution profile, contour plots and 3D graphs were generated. The 3D graph (as shown in Figure $6(\mathrm{a})$ ) for $\mathrm{rel}_{2} \mathrm{Hr}$ shows that percent drug release at second hour is plotted on $y$-axis where as the concentrations of excipients were plotted on $x$ - and $z$-axis. As the concentration of carboxymethyl xyloglucan and HPMC K100M increased from 180 to $200 \mathrm{mg}$ and 10 to $30 \mathrm{mg}$, respectively, the percent drug release decreased signifying that the polymers have definite effect on drug release, and especially along the axis region of HPMC-K-100M the effect was greater at lower concentration which indicate its effectiveness in controlling burst release is prominent at lower level, whereas the increasing concentration of DCP shows significant effect on drug release at lowest concentration. The contour plot (as shown in Figure 6(b)) for $\mathrm{rel}_{2} \mathrm{Hr}$ justifies that optimum

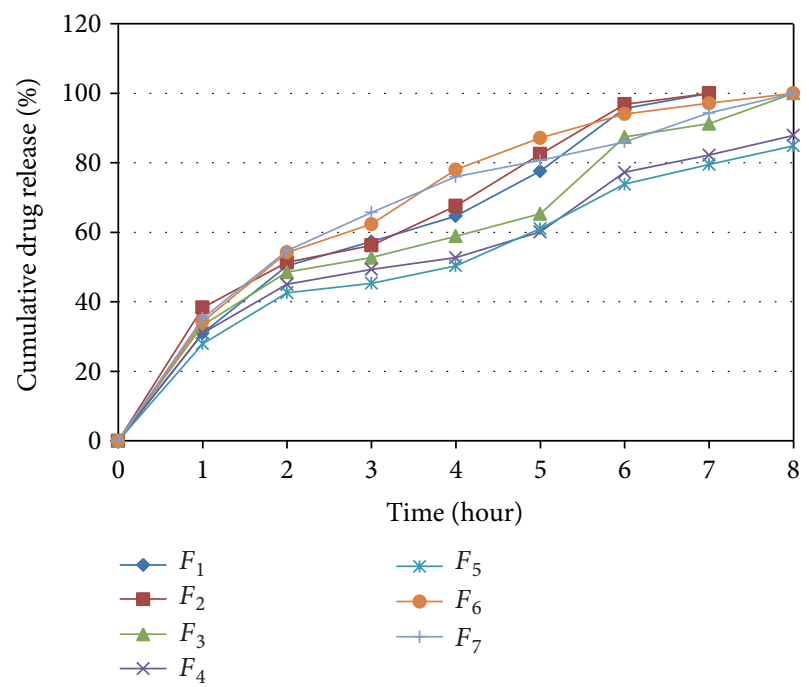

FIGURE 5: Dissolution profile for batches $F_{1}$ to $F_{7}$.

formulation complying with the acceptance criteria can be achieved by selecting the formulations near to the upper left side of the triangle-shaped contour plot which is the diagram obtained from the evaluation result of $\left(F_{1}-F_{7}\right)$ formulations. Almost similar results were observed with $3 \mathrm{D}$ graph (as shown in Figure 7(a)) and contour plot (as shown in Figure 7 (b)) for $\mathrm{rel}_{8} \mathrm{Hr}$. Here as the concentration of carboxymethyl xyloglucan increased release retardation effect, also increases due to increase in the diffusion path length and DCP is showing its effect at lower concentration but not at higher concentration, while HPMC-K-100 M is helping to control burst release in initial hours but not showing any release retarding effect at eight hour because it is used in a smaller quantity.

From the dissolution study of seven batches (Figure 5), percent release of drug at two hours $\left(\mathrm{rel}_{2} \mathrm{Hr}\right)$ was found to be in range of $27.93 \%$ to $38.33 \%$ and percent release of drug at eight hour $\left(\mathrm{rel}_{8} \mathrm{Hr}\right)$ was found to be in range of $84.90 \%$ to $100.21 \%$.

3.3.1. Percent Drug Release at Second Hour ( $\mathrm{rel}_{2} \mathrm{Hr}$ ). Statistical optimization was carried out in Design-Expert software 
TABLe 5: Dissolution model for $F_{1}$ to $F_{7}$ formulations.

\begin{tabular}{lcccc}
\hline Batch code & Release exponent $(n)$ & Kinetic constant $(K)$ & $R$ & Best fit model \\
\hline$F_{1}$ & 0.5919 & 30.8556 & 0.9874 & Matrix \\
$F_{2}$ & 0.5030 & 36.2863 & 0.9828 & Matrix \\
$F_{3}$ & 0.5171 & 31.8826 & 0.9845 & Matrix \\
$F_{4}$ & 0.5008 & 29.6438 & 0.9870 & Matrix \\
$F_{5}$ & 0.5301 & 27.1364 & 0.9897 & Matrix \\
$F_{6}$ & 0.5814 & 36.9647 & 0.9955 & Matrix \\
$F_{7}$ & 0.5049 & 36.9443 & 0.9957 & Matrix \\
\hline
\end{tabular}

Non-Fickian.

Design-Expert software

Component coding: actual

Release at $2 \mathrm{hr}(\%)$

- Design points above predicted value

- Design points below predicted value

$\int_{42.57}^{54.64}$

$X_{1}=A:$ Cm TSP

$X_{2}=B:$ HPMC

$X_{3}=C: \mathrm{DCP}$

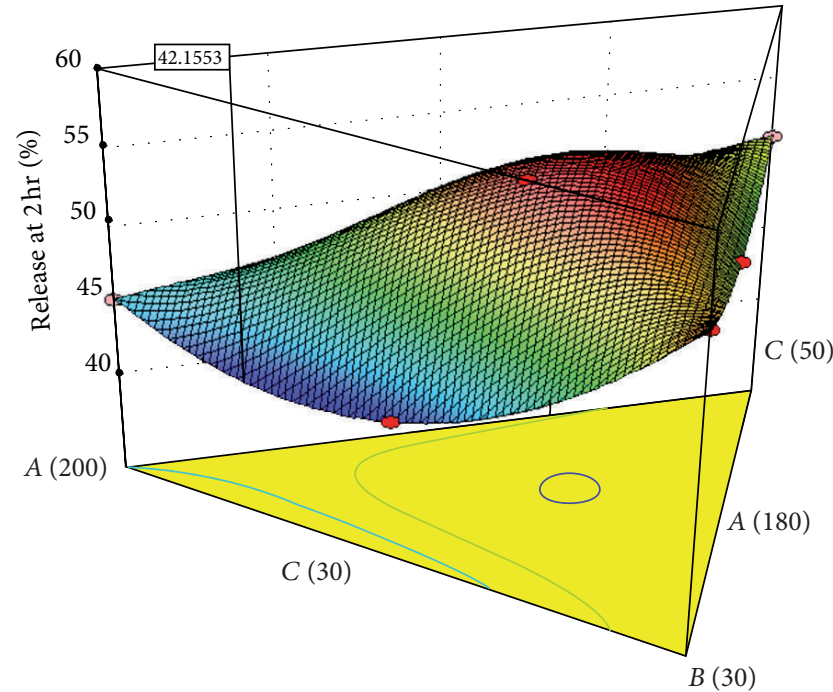

(a) $3 \mathrm{D}$ graph of percent drug release at 2 nd hour

Design-Expert software

Component coding: actual

Release at $2 \mathrm{hr}(\%)$

- Design points

54.64

42.57

$X_{1}=A:$ Cm TSP

$X_{2}=B:$ HPMC

$X_{3}=C: \mathrm{DCP}$

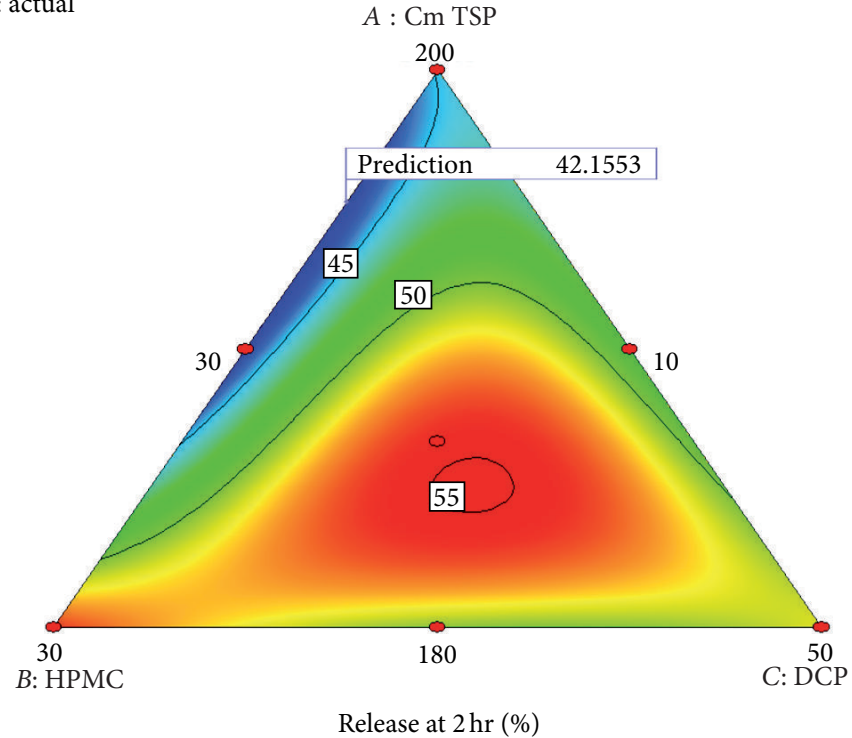

(b) Contour plot for percent drug release at 2 nd hour

FIGURE 6: Contour plot showing amount of drug release at second hour $\left(Y_{1}\right)$ using different combinatinon, of $X_{1}, X_{2}$, and $X_{3}$. The contour lines showing percentage of drug release at the end of second hour. 
TABLE 6: Pre- and postcompression properties of optimization batches $F_{1}-F_{7}$.

\begin{tabular}{|c|c|c|c|c|c|c|c|}
\hline Parameters & $F_{1}$ & $F_{2}$ & $F_{3}$ & $F_{4}$ & $F_{5}$ & $F_{6}$ & $F_{7}$ \\
\hline Bulk density (g/mL) & $0.387 \pm 0.22$ & $0.355 \pm 0.17$ & $0.303 \pm 0.11$ & $0.409 \pm 0.30$ & $0.343 \pm 0.11$ & $0.318 \pm 0.16$ & $0.366 \pm 0.15$ \\
\hline ty $(\mathrm{g} / \mathrm{mL})$ & $442 \pm 0.14$ & $0.416 \pm 0$ & $0.426 \pm 0$ & $0.493 \pm 0$ & $0.428 \pm$ & $0.374 \pm 0.04$ & \\
\hline Angle & $27.78 \pm 0$ & $26.05 \pm 0$ & $25.55 \pm$ & 29 & $3.08+0$ & 27.0 & $26.06 \pm 0.04$ \\
\hline & $13.44 \pm 0.14$ & $12.66 \pm 0.11$ & 0 & $14.43 \pm 0$ & $14.06 \pm$ & & $17 \pm 0.15$ \\
\hline & $1.14 \pm 0.18$ & $1.17 \pm 0.28$ & $1.41 \pm 0.07$ & $1.21 \pm 0.28$ & $1.24 \pm$ & $1.17 \pm$ & $1.13 \pm 0.11$ \\
\hline ess $\left(\mathrm{kg} / \mathrm{cm}^{2}\right)$ & $5.1 \pm 0.33$ & $5.3 \pm 0.26$ & $5.5 \pm 0.18$ & $5.4 \pm 0.34$ & $5.7 \pm 0.17$ & $5.5 \pm 0.32$ & $5.4 \pm 0.13$ \\
\hline Friabil & $0.74 \pm 0.21$ & $0.70 \pm 0.11$ & $0.57 \pm 0.22$ & $0.62 \pm 0.16$ & $0.42 \pm 0.12$ & & $0.67 \pm 0.22$ \\
\hline ity of weight (mg) & $378.29 \pm 0.34$ & $379.78 \pm 0.45$ & $378.98 \pm 0.55$ & $381.19 \pm 0.36$ & $382.4 \pm 0.12$ & $378.56 \pm 0.24$ & $381.78 \pm 0.13$ \\
\hline tent $(\%)$ & $100.22 \pm 0.22$ & $100.62 \pm 0.11$ & $99.14 \pm 0.18$ & $98.34 \pm 0.39$ & $98.72 \pm 0.21$ & $101.16 \pm 0.67$ & $98.52 \pm 0.89$ \\
\hline Thickness (mm) & $4.40 \pm 0.014$ & $4.17 \pm 0.016$ & $3.89 \pm 0.026$ & $4.29 \pm 0.016$ & $4.02 \pm 0.031$ & $4.22 \pm 0.014$ & $3.83 \pm 0.034$ \\
\hline
\end{tabular}

$\pm \mathrm{SD}$ (standard deviation) $n=3$.

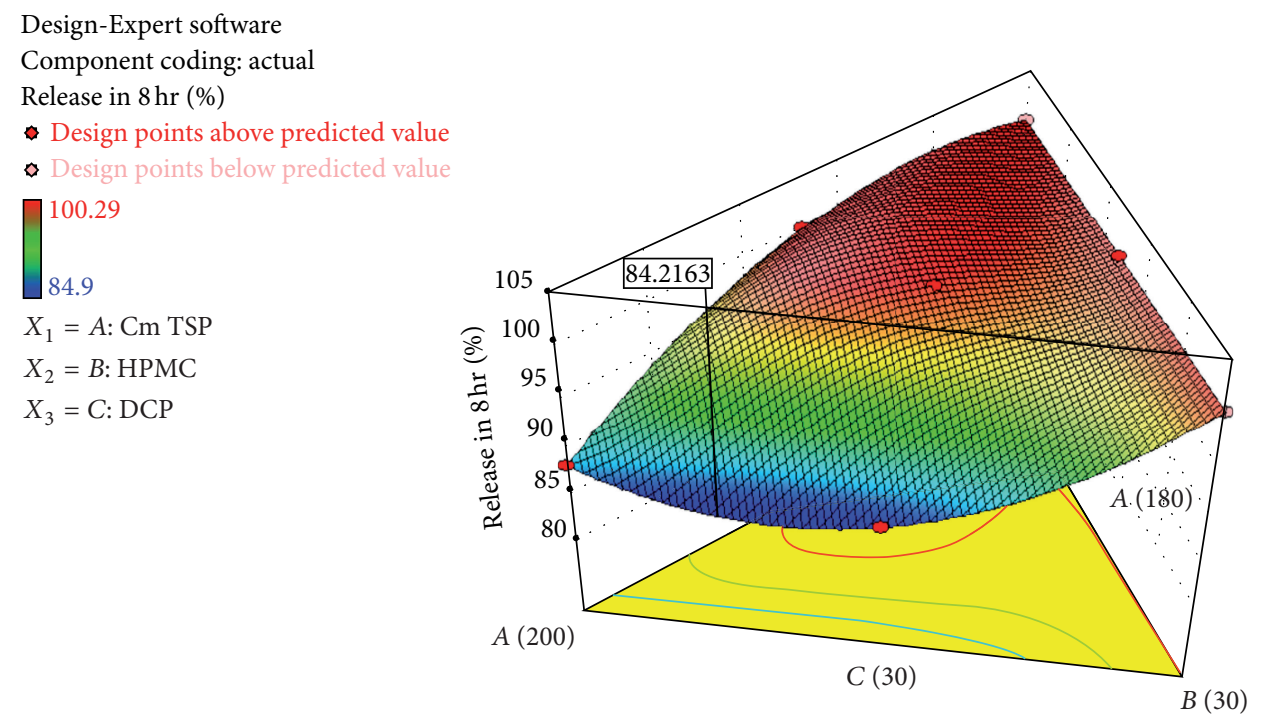

(a) 3D graph and Contour plot of percent drug release at 8 th hour

Design-Expert software

Component coding: actual Release in $8 \mathrm{hr}(\%)$

- Design points

100.29

84.9

$X_{1}=A:$ Cm TSP

$X_{2}=B: H P M C$

$X_{3}=C: \mathrm{DCP}$

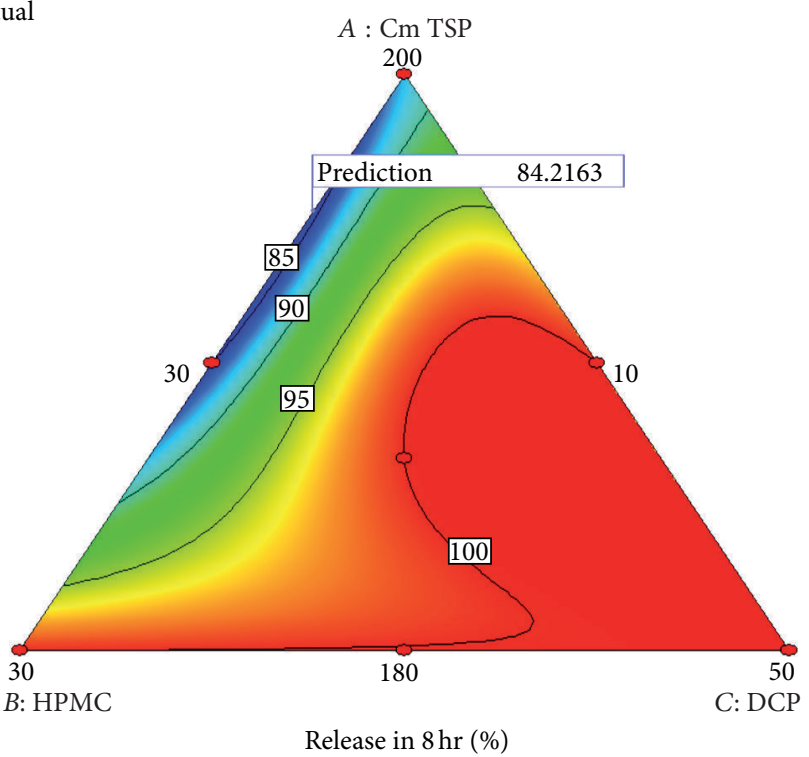

(b) Contour plot of percent drug release at 8 th hour

Figure 7: Contour plot showking amount of drug release at twelfth hour $\left(Y_{2}\right)$ using different combinatinon of $X_{1}, X_{2}$, and $X_{3}$. The contour lines showing percentage of drug release at the end of twelfth hour. 
TABLE 7: Composition of optimum formulations $B_{1}, B_{2}$, and $B_{3}$.

\begin{tabular}{lccc}
\hline Composition (mg) & \multicolumn{3}{c}{ Formulations } \\
& $B_{1}$ & $B_{2}$ & $B_{3}$ \\
\hline Tramadol HCl & 100 & 100 & 100 \\
Carboxymethyl xyloglucan & 194.39 & 190.606 & 200 \\
HPMC-K-100M & 15.610 & 19.394 & 30 \\
DCP & 30 & 5 & 30 \\
Talc & 5 & 5 & 5 \\
Magnesium stearate & 5 & 30 & 5 \\
PVP K-30 & 30 & qs. & 30 \\
Isopropyl alcohol & qs. & & qs. \\
\hline
\end{tabular}

TABLE 8: Pre- and postcompression properties of optimized carboxymethyl xyloglucan matrix tablets.

\begin{tabular}{lccr}
\hline Parameters & $B_{1}$ & $B_{2}$ & $B_{3}$ \\
\hline Bulk density & $0.312 \pm 0.19$ & $0.331 \pm 0.22$ & $0.376 \pm 0.16$ \\
Tapped density & $0.351 \pm 0.24$ & $0.348 \pm 0.13$ & $0.397 \pm 0.09$ \\
Angle repose & $25.03 \pm 0.07$ & $27.31 \pm 0.11$ & $29.27 \pm 0.03$ \\
Carr's index & $13.01 \pm 0.20$ & $13.22 \pm 0.17$ & $14.21 \pm 0.13$ \\
Hausner's ratio & $1.12 \pm 0.21$ & $1.05 \pm 0.19$ & $1.06 \pm 0.14$ \\
Hardness & $5.2 \pm 0.03$ & $5.1 \pm 0.01$ & $5.3 \pm 0.04$ \\
Friability & $0.542 \pm 0.07$ & $0.481 \pm 0.16$ & $0.768 \pm 0.18$ \\
Weight variation & $365 \pm 1.79$ & $387 \pm 0.93$ & $395 \pm 1.04$ \\
Drug content & $99.69 \pm 0.17$ & $98.61 \pm 0.02$ & $98.14 \pm 0.11$ \\
Thickness $(\mathrm{mm})$ & $3.82 \pm 0.03$ & $3.96 \pm 0.06$ & $4.17 \pm 0.01$ \\
\hline
\end{tabular}

$\pm \mathrm{SD}$ (standard deviation) $n=3$.

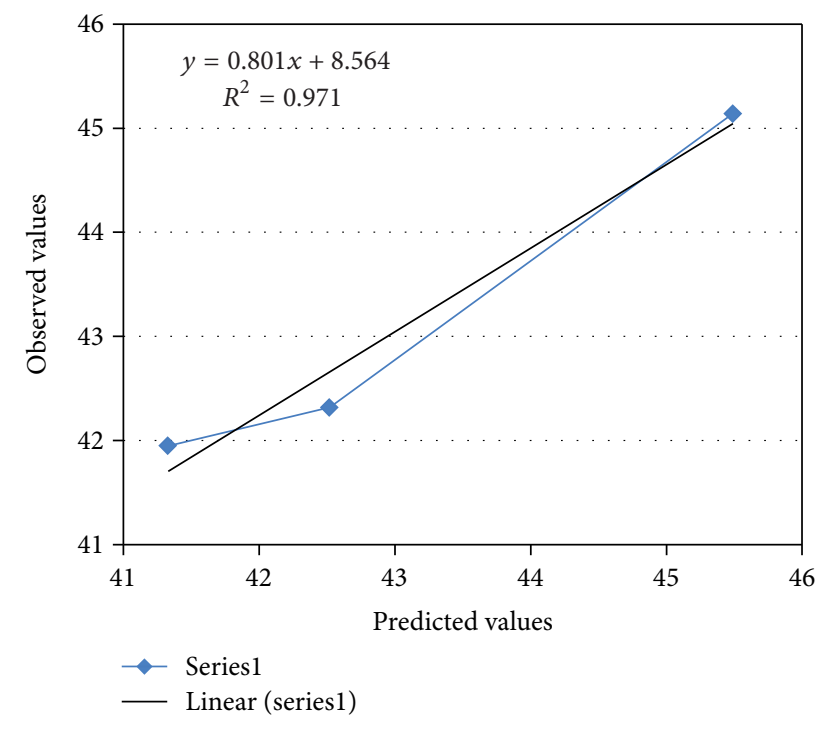

FIGURE 8: Linear correlation plot for release at 2nd hour.

(version 8.0.5), which suggested that special cubic model (SCM) was followed for release at two hour that with $P$ value of 0.0409 . This indicated that the model was significant. Therefore, SCM was selected for percent release at two hours $\left(\mathrm{rel}_{2} \mathrm{Hr}\right)$. In order to find out the contribution of each components and their interaction, analysis of variance (ANOVA) for SCM was carried. Table 10 shows the results of the analysis of variance (ANOVA), which was used to generate mathematical models. The model $F$-value (344.65) implied that the model was significant. Value of probability $(P)$ less than 0.05 indicates that model terms were significant. In this case, linear mixture components, $A B, B C$, and $A B C$, were significant model terms

The equation for percent drug release at the end of the second hour is

$$
\begin{aligned}
Y_{1}= & +45.15 * A+54.19 * B+51.44 * C \\
& -28.40 * A * B-9.78 * B * C \\
& +232.81 * A * B * C,
\end{aligned}
$$

where, $A$ is the carboxymethyl xyloglucan, $B$ is the HPMC, $C$ is the DCP, $Y_{1}$ is the \% release at second hour.

3.3.2. Percent Drug Release at Eighth Hour ( $\mathrm{rel}_{8} \mathrm{Hr}$ ). Model adequacy was checked for percent drug release at eighth hour $\left(\mathrm{rel}_{8} \mathrm{Hr}\right)$. Model gave the highest order polynomial where the additional terms were significant and the model was selected. The SCM suggested by the software followed for ( $\mathrm{rel}_{8} \mathrm{Hr}$ ), with $P$-value 0.0004 and this indicated the model was highly significant. In order to find out contribution of each component and their interaction, ANOVA for SCM was carried out. The model $F$-value of 326887 implied that the model was highly significant. Value of $P$ less than 0.05 indicates that model terms were significant. In this case, linear mixture components $A B, A C$, and $A^{2} B C$ were significant 
TABLE 9: The predicted and experimental values of response variables, and their percentage prediction error for $B_{1}, B_{2}$, and $B_{3}$ formulations.

\begin{tabular}{lcccc}
\hline Optimized formulation & Response variable & Experimental value & Predicted value & Percentage prediction error \\
\hline \multirow{2}{*}{$B_{1}$} & $Y_{1}$ & $41.33 \%$ & $41.95 \%$ & -1.44 \\
& $Y_{2}$ & $83.78 \%$ & $83.98 \%$ & -0.238 \\
\hline \multirow{2}{*}{$B_{2}$} & $Y_{1}$ & $42.52 \%$ & $42.32 \%$ & +0.47 \\
\hline \multirow{2}{*}{$B_{3}$} & $Y_{2}$ & $84.92 \%$ & $84.56 \%$ & +0.425 \\
& $Y_{1}$ & $45.49 \%$ & $45.14 \%$ & +0.775 \\
\end{tabular}

TABLE 10: Analysis of variance (ANOVA) for all two responses.

\begin{tabular}{|c|c|c|c|c|c|}
\hline \multirow{3}{*}{ Source } & \multicolumn{2}{|c|}{$\%$ Release at 2 hour } & \multirow{3}{*}{ Source } & \multicolumn{2}{|c|}{$\%$ Release at 8 hour } \\
\hline & & & & & \\
\hline & $F$-value & $P$ value & & $F$-value & $P$ value \\
\hline Model & 344.65 & 0.0409 & Model & 272.39 & 0.004 \\
\hline Linear mixture & 389.03 & 0.0358 & Linear mixture & 162.92 & 0.0003 \\
\hline$A B$ & 490.78 & 0.0287 & $A B$ & 56.11 & 0.0003 \\
\hline$B C$ & 58.17 & 0.0830 & $A C$ & 23.94 & 0.0005 \\
\hline$A B C$ & 741.53 & 0.0234 & $A^{2} B C$ & 19.97 & 0.0006 \\
\hline
\end{tabular}

TABLE 11: Similarity factor determination.

\begin{tabular}{lcc}
\hline Optimized formulations & $f_{2}$ value & Consideration \\
\hline$B_{1}$ & 75 & Similar \\
$B_{2}$ & 70 & Similar \\
$B_{3}$ & 61 & Similar \\
\hline
\end{tabular}

model terms. The equation for percent drug release at the end of eighth hour is

$$
\begin{aligned}
Y_{2}= & +87.89 * A+100.00 * B+100.29 * C \\
& -36.18 * A * B+23.64 * A * C \\
& +431.97 * A_{2} * B * C,
\end{aligned}
$$

where $A$ : carboxymethyl xyloglucan, $B$ : HPMC, and $C$ : DCP, $Y_{2}$ : \% release at eighth hour.

3.3.3. Search for Optimum Formulation. Based on acceptance criteria and desirability factor, Design-Expert suggested three optimum formulations $B_{1}, B_{2}$, and $B_{3}$ (as shown in Table 7 ). The values of desirability closest to 1 is considered most favourable. The values of desirabilities for three optimized formulations $B_{1}, B_{2}$, and $B_{3}$ were $0.999,0.987,0.786$, respectively. Optimized batches were formulated with the suggested composition. The physicochemical evaluation (as shown in Table 8) of optimum formulations showed good flow properties and excellent compression characteristics.

3.4. Validation of Optimized Model. For all three optimized formulations, the results of the physical evaluations and tablet assay were found to be within limits. Figures 8 and 9 show linear correlation plots drawn between the predicted and observed response variables. These plots demonstrated higher values of $R$ as 0.971 and 0.969 for release at 2 nd

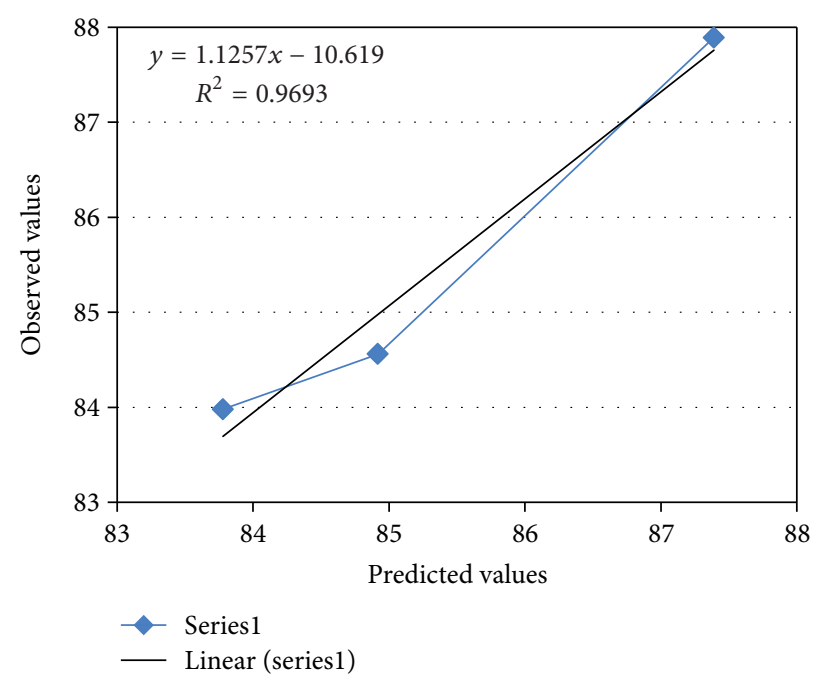

FIgURE 9: Linear correlation plot for release at 8th hour.

hour and release at 8 th hour, respectively, indicating a good correlation. Upon comparison of the observed responses with that of the anticipated responses, the prediction error varied between $-1.44 \%$ and $+0.775 \%$ as shown in Table 9 . Thus, the low magnitudes of error as well as the significant values of $R^{2}$ in the current study indicate a high prognostic ability of the software.

The optimization batches were subjected to short-term stability studies at $40^{\circ} \mathrm{C}$ and $75 \%$ relative humidity $(\mathrm{RH})$ for 3 months. Samples withdrawn after 3 months showed no significant change in dissolution studies and drug content.

\section{Conclusion}

Sustained drug release following matrix kinetics attained in the current study indicates that the hydrophilic matrix tablet 
TABLE 12: Trial batch formulations of plain xyloglucan and carboxymethyl xyloglucan.

\begin{tabular}{lcc}
\hline Ingredients & \multicolumn{2}{c}{ Formulations } \\
& $M_{1}$ & $M_{2}$ \\
\hline Tramadol HCl & 100 & 100 \\
TSP & 150 & - \\
CM-TSP & - & 150 \\
DCP & 20 & 20 \\
Talc & 5 & 5 \\
Magnesium stearate & 5 & 5 \\
PVP K-30 & 30 & 30 \\
Isopropyl alcohol & qs. & qs. \\
\hline Total & 310 & 310 \\
\hline
\end{tabular}
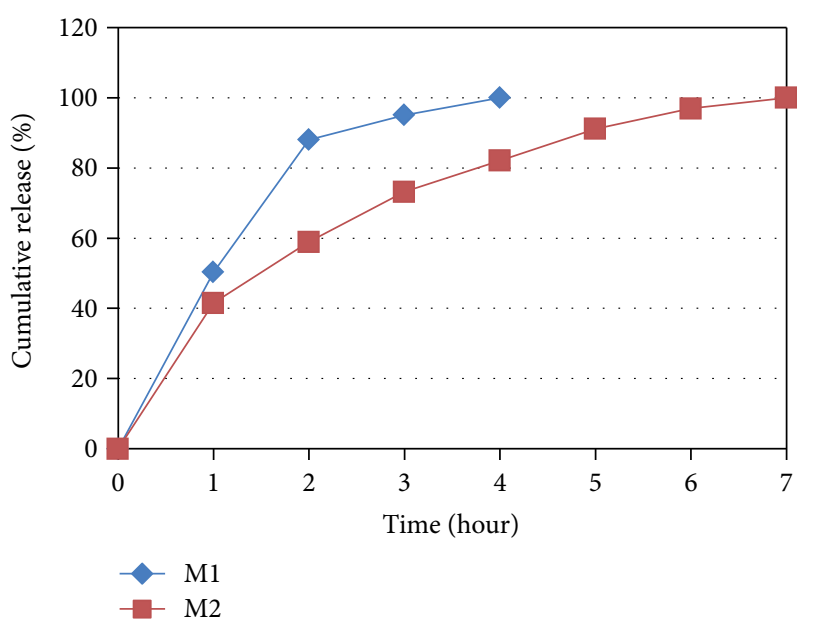

FIgURE 10: Dissolution profile for batches $M_{1}$ to $M_{2}$.

prepared using carboxymethyl xyloglucan and HPMC-K$100 \mathrm{M}$ can successfully be employed sustain the drug release up to 8 to 12 hours as shown in Table 5. carboxymethyl xyloglucan played major role in sustaining release of tramadol at later stage of release profile, whereas HPMC-K$100 \mathrm{M}$ prevented the burst effect by controlling the sudden release of drug from the dosage form at the initial stage of the release profile. It was concluded that appropriate balancing between various levels of the polymers may contribute better results. High degree of prognosis obtained using RSM corroborates that a simplex centroid design is quite efficient in optimizing drug delivery systems.

\section{References}

[1] P. Colombo, R. Bettini, G. Massimo, P. L. Catellani, P. Santi, and N. A. Peppas, "Drug diffusion front movement is important in drug release control from swellable matrix tablets," Journal of Pharmaceutical Sciences, vol. 84, no. 8, pp. 991-997, 1995.

[2] P. S. Rao, T. P. Ghosh, and S. Krishna, "Extraction and purification of tamarind seed polysaccharide," Journal of Scientific \& Industrial Research, vol. 4, article 705, 1946.

[3] M. Sano, E. Miyata, S. Tamano, A. Hagiwara, N. Ito, and T. Shirai, "Lack of carcinogenicity of tamarind seed polysaccharide in
B6C3F1 mice," Food and Chemical Toxicology, vol. 34, no. 5, pp. 463-467, 1996.

[4] S. Burgalassi, L. Panichi, M. F. Saettone, J. Jacobsen, and M. R. Rassing, "Development and in vitro/in vivo testing of mucoadhesive buccal patches releasing benzydamine and lidocaine," International Journal of Pharmaceutics, vol. 133, no. 1-2, pp. 1-7, 1996.

[5] D. Kulkarni, A. K. Dwivedi, J. P. S. Sarin, and S. Singh, "Tamarind seed polyose: a potential polysaccharide for sustained release of verapamil hydrochloride as a model drug," Indian Journal of Pharmaceutical Sciences, vol. 59, no. 1, pp. 1-7, 1997.

[6] M. F. Saettone, S. Burgalassi, B. Giannaccini, E. Boldrini, P. Bianchini, and G. Luciani, "Ophthalmic solutions viscosified with tamarind seed polysaccharide," PCT International Application WO, vol. 97, no. 28, p. 787, 1997.

[7] P. Goyal, V. Kumar, and P. Sharma, "Carboxymethylation of Tamarind kernel powder," Carbohydrate Polymers, vol. 69, no. 2, pp. 251-255, 2007.

[8] L. J. Scott and C. M. Perry, "Tramadol: a review of its use in perioperative pain,” Drugs, vol. 60, no. 1, pp. 139-176, 2000.

[9] T. Salsa, F. Veiga, and M. E. Pina, "Oral controlled-release dosage forms. I. Cellulose ether polymers in hydrophilic matrices," Drug Development and Industrial Pharmacy, vol. 23, no. 9, pp. 929-938, 1997.

[10] J. Cooper and C. Gunn, "Powder flow and compaction," in Tutorial Pharmacy, S. J. Carter, Ed., pp. 211-233, CBS Publishers, New Delhi, India, 1986.

[11] D. Shah, Y. Shah, and R. Pradhan, "Development and evaluation of controlled-release diltiazem $\mathrm{HCl}$ microparticles using cross-linked poly(vinyl alcohol)," Drug Development and Industrial Pharmacy, vol. 23, no. 6, pp. 567-574, 1997.

[12] M. E. Aulton and T. I. Wells, Pharmaceutics: The Science of Dosage Form Design, Churchill Livingstone, London, UK, 1988.

[13] Pharmacopoeia of India, Ministry of Health and Family Welfare, Government of India, New Delhi, India, 1996.

[14] J. G. Wagner, "Interpretation of percent dissolved-time plots derived from in vitro testing of conventional tablets and capsules," Journal of Pharmaceutical Sciences, vol. 58, no. 10, pp. 1253-1257, 1969.

[15] MatrixT, "Mechanism of sustained action medication: theoretical analysis of rate of release of solid drugs dispersed in solid matrices," Journal of Pharmaceutical Sciences, vol. 52, pp. 1145-1149, 1963.

[16] A. W. Hixon and J. H. Crowell, "Dependence of reaction velocity upon surface and agitation," Industrial \& Engineering Chemistry, vol. 23, pp. 923-931, 1931.

[17] R. W. Korsmeyer, R. Gurny, and E. Doelker, "Mechanisms of solute release from porous hydrophilic polymers," International Journal of Pharmaceutics, vol. 15, no. 1, pp. 25-35, 1983.

[18] N. A. Peppas, "Analysis of Fickian and non-Fickian drug release from polymers," Pharmaceutica Acta Helvetiae, vol. 60, no. 4, pp. 110-111, 1985.

[19] M. Bamba, F. Puisieux, J. P. Marty, and J. T. Carstensen, "Release mechanisms in gelforming sustained release preparations," International Journal of Pharmaceutics, vol. 2, no. 5-6, pp. 307-315, 1979.

[20] S. Jain, S. K. Yadav, and U. K. Patil, "Preparation and evaluation of sustained release matrix tablet of furosemide using natural polymers," Research Journal of Pharmacy and Technology, vol. 1, article 375, no. 4, 2008. 
[21] The European agency for the evaluation of medicinal products (EMEA), "Human medicines evaluation unit, note for guidance on quality of modified release products: oral dosage forms," CPMP/QWP/96(I):604, 1999.

[22] L. Lachman, H. Lieberman, and J. Kaning, The Theory and Practice of Industrial Pharmacy, Lei \& Feiberger, Philadelphia, Pa, USA, 3rd edition, 1970.

[23] R. B. Miller, S. T. A. Malkowska, W. Wimmer et al., "A controlled release preparation for oral administration contains tramadol, or a pharmaceutically acceptable salt thereof, as active ingredient," US Patent no. 6, 254, 887, 2001. 

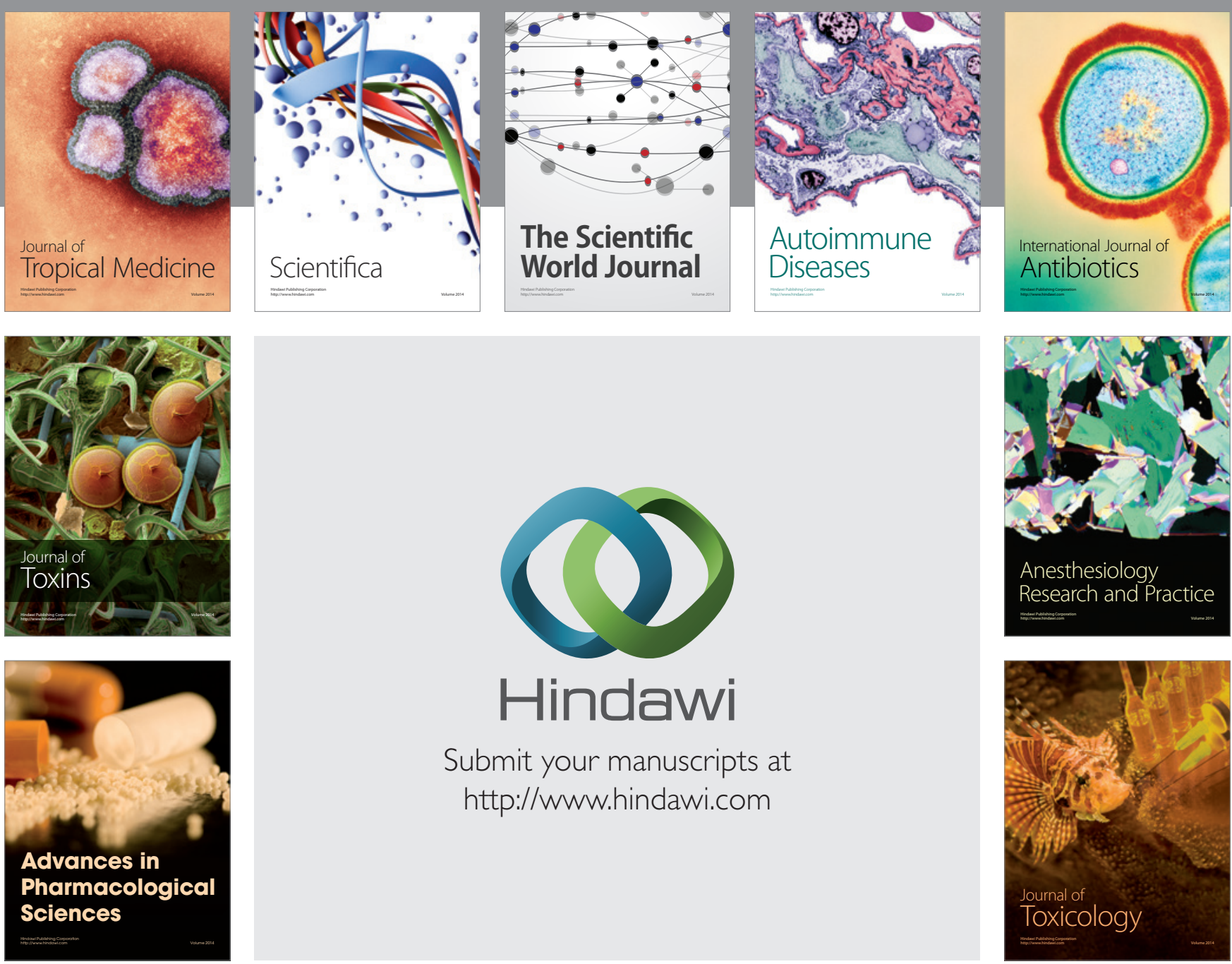

\section{Hindawi}

Submit your manuscripts at

http://www.hindawi.com
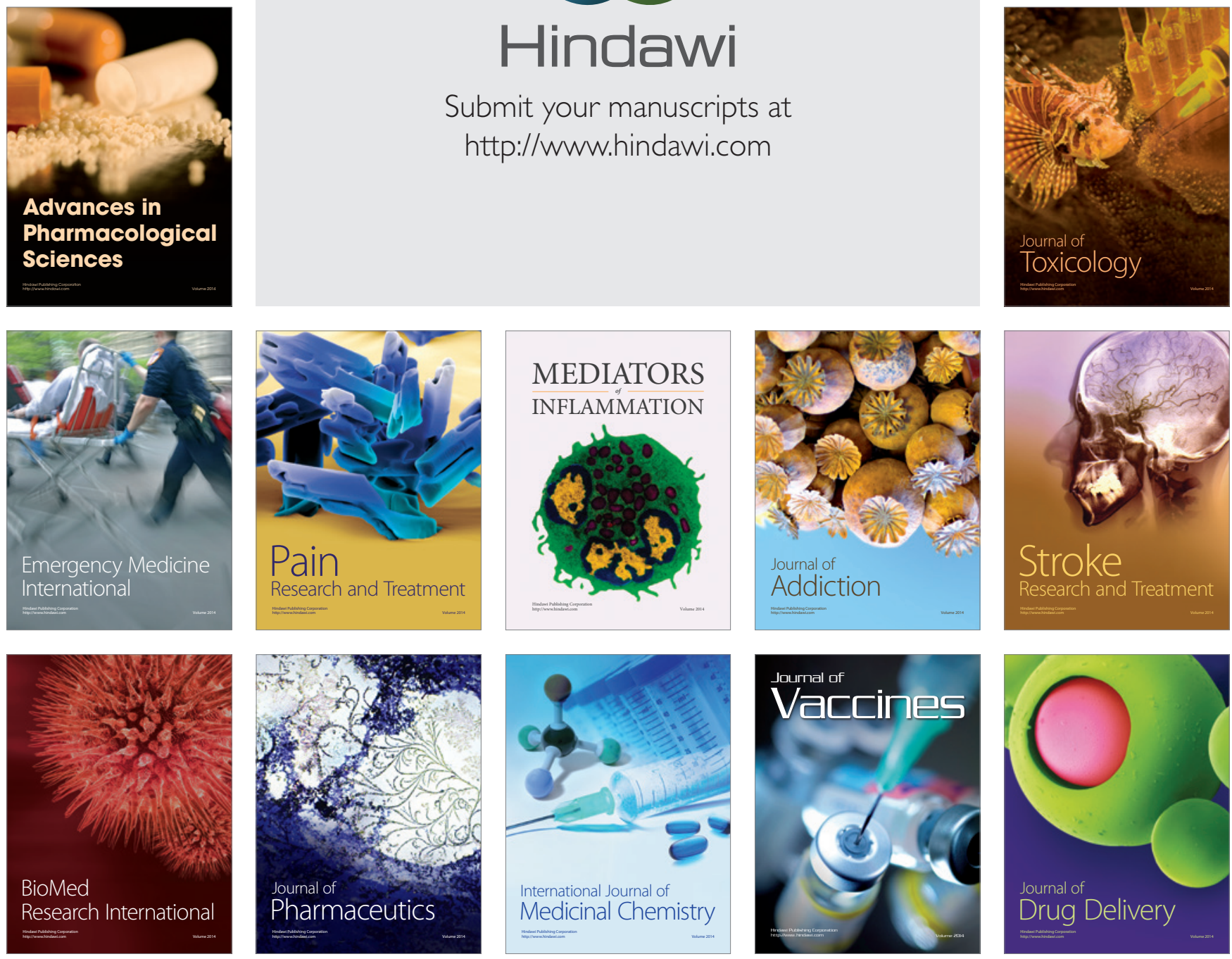